ARTICLE

https://doi.org/10.1057/s41599-019-0270-5

\title{
What principle of difference for a truly egalitarian social democracy? Rereading Rawls after social democracy's failures
}

\author{
André Barata ${ }^{1} \&$ Maria João Cabrita ${ }^{1}$
}

\begin{abstract}
Social democracy based on welfare and the redistribution of social contributions is failing. The accumulation of wealth and the increase in inequalities are the two faces of Janus that social democracy has not been able to contain over the recent decades. In this context, it matters to discuss John Rawls's influential difference principle. According to the maximin criterion put forth by Rawls, it does not suffice that no one becomes worse off; those who are worse off must also become better off than they are. Here, we note that the existence and growth of inequality find no opposition in the maximin rule. Despite appearances, strictly speaking it merely introduces a factor of social compensation, a sort of "assistencialism" to the victims of the greatest inequality. Even the most robust formulation of the principle of difference, according to which the greatest advantage to the less advantaged is indispensable, does not per se preclude an aggregate growth of inequalities. It seems clear that it was an egalitarian goal what Rawls had in mind in A Theory of Justice. Rawls's critical comments on welfare capitalism must indeed not be forgotten-especially in his further explanations about the application of the principles of justice in a property-owning democracy. Here, as in liberal socialism, the dispersion of property, capital and resources prevents economic and political powers from being concentrated into the hands of a minority. However, the egalitarian aim does not strictly follow from the difference principle as stated, whether taken literally as an application of the maximin rule or inferring from its strongest formulation. A reformulation that does justice to the egalitarian aim of the principle of difference is, however, possible: namely, a degrowthist reformulation, truly requiring a degrowth in accumulation and inequalities, making explicit a brake clause that hinders the aggregate growth of inequalities. Such a degrowthist conception of the difference principle may justify some concrete rules that are able to enforce the egalitarian commitments of social democracy.
\end{abstract}

\footnotetext{
${ }^{1}$ Praxis-Centre of Philosophy, Politics and Culture, University of Beira Interior, Covilha, Portugal. Correspondence and requests for materials should be addressed to A.B. (email: andrebaratanascimento@gmail.com)
} 
The difficulties facing social democracy today and the debate on Rawls's difference principle

here is no doubt today that social democracy based on the welfare state and on the redistributive social transfers is failing. On this topic, data found in Overview of Inequality Trends, Key Findings and Policy Directions (2015) is particularly enlightening. It indicates a significant increase in inequalities in OECD countries based on a comparison of data from the mid1980s with data from 2013 or more recent years. It is important to monitor the evolution of inequalities in OECD countries because there has been, until the most recent years, a pattern of correcting inequalities by way of redistribution policies. In fact, such policies in these countries have been getting weaker, and the capacity for correcting inequalities diminishing. Therefore, notable increases in Gini coefficients have been recorded in countries subject to severe tax consolidation policies (as a result of the debt crisis), but also in countries such as Sweden and New Zealand (OECD, 2015, p. 24).

Inequalities are increasing, as is the concentration of wealth, despite traditional social transfers. This follows a trend dating back to the end of the 1970s in English-speaking countries such as the USA and the UK. The trend spread to other OECD member countries in the 1980s, and has had a significant effect since the turn of the millennium in OECD states with the lowest levels of income inequality, such as the Scandinavian countries.

In fact, the accumulation of wealth and the escalation in inequalities are two faces of Janus that social democracy has been unable to contain. Perhaps simply under an illusion, we are driven to say that real social democracy has been failing for decades in the face of an increasingly unequal world. Perhaps, taking advantage of the ambivalence between egalitarianism and welfare capitalism, social democracy has leaned towards the latter. The idea of social democracy's ambivalence should be taken seriously. Indeed, it is symptomatic that John Rawls himself recognises, in Justice as Fairness (2001), as a serious failing of A Theory of Justice (1971), that it did not sufficiently underscore the contrast between welfare capitalism and property-owning democracy. Without going too far in our interpretation, we can say that the risks of ambivalence in the understanding of Rawls's $A$ Theory of Justice (TJ), identified by the author himself, are equivalent to the risks of ambivalence in social democracy roughly since the 1970s.

In terms of emphasis, it is necessary to acknowledge dangers such as those recently raised by Walter Scheidel in The Great Leveler: Violence and the History of Inequality from the Stone Age to the Twenty-First Century (2017). Its primary and controversial thesis is that over time the greatest social levelers, which have actually corrected accumulated inequalities, have always been one of four: great epidemics, state collapses, wars that involve mass mobilisation, and revolutionary movements that change social order. Scheidel's thesis should concern us. The conditions that make it possible for inequalities to grow are largely the result of accumulation processes at times of economic growth and peace. They involve stable periods that run smoothly, protected by laws that guarantee continuity and the rights that this continuity produces. The violence of wars or revolutions, or even a massive natural disaster, interrupts that continuity. The bitter irony is that these "great levelers" that are increasingly within the reach of human hands are, although destructive, desires; and the greater the inequalities, the more such desires there will be. This was the case in the early decades of the 20th century and it is crucial for us to understand that the same thing will happen again if we continue to widen the opportunity gap in contemporary societies. What is important to retain here is not so much that violence has historically been a great leveler but that significant unevenness has been the source and stage for mass violence. There is no alternative between evils, but rather two evils that mutually feed each other in a cycle that, with enough historical retrospection, reveals itself to be truly infernal. The alternative must therefore be an alternative to past history. Piketty (2013) has also given historical evidence that the periods of the 20th century when there were reversals in the accumulation of inequalities in Europe were during the two great wars.

Within this theoretical and historical framework that forms an indisputable trend towards greater inequalities in places where social democratic models have taken precedence, we propose revisiting and returning to the discussion of the concept of social justice, which has become more precious to social democracy and progressivism in general. In particular, returning to a discussion of John Rawls's famous difference principle (DP) within the framework of principles that form the concept of justice proposed by the philosopher in the hope that overcoming its ambivalence could be the key to overcoming the corresponding ambivalence of social democracy itself.

According to the DP, inequalities are not fair from a utilitarian viewpoint, which aims for the greatest good for the greatest number. Rightly so, since this means it is unacceptable to sacrifice minorities and individuals. Neither are inequalities acceptable under a criterion that complies with Pareto optimality, in which inequalities are acceptable until someone is harmed. This would make anything licit, as long as the condition that no one is harmed is completely satisfied; as though there were nothing wrong with inequality in itself-inequality being, by very definition, relative to others. In the debate with rivals in the field of rational choice theory, the maximin criterion put forth by Rawls is more exacting: it does not suffice that no one becomes worse off; also those who are worse off must become better off than they are. Put simply, this criterion precludes objection to Pareto optimality. With barely more than a few crumbs, the maximin rule can be met. And while, with greater conviction, this strategy can counter and indeed diminish the most extreme poverty, it is no less true that it allows for a boundless growth of inequalities. The existence and growth of inequality find no opposition in the maximin rule, which, despite appearances, merely introduces a factor of social compensation, a sort of "assistencialism" to the victims of the greatest inequality.

What would it take, then? Starting with a negative: that those in the worst conditions might see their circumstances somewhat improved is not enough to justify allowing inequalities to increase. The inequalities that are inevitable in any free, nontotalitarian society become acceptable when, and only when, inequalities are not allowed to increase. Most likely this was what Rawls had in mind in TJ, though it does not necessarily follow from the explicit outline of his principles of justice, namely his difference principle, particularly if taken literally as an application of the maximin rule.

A maximin strategy without assistencialism should not circumvent the demand to not increase the curve of inequality. But how to ensure that it does not allow it? Considerations outside the formulation of his own principles of justice are not enough, however explicit they may be, such as when Rawls says: "The even larger difference between classes violates the principle of mutual advantage as well as democratic equality" (TJ, revised edition, p. 68s).

Van Parijs has expressed similar dissatisfaction, as well as noted a significant variation in how the DP is formulated, concluding that the last of such formulations would be immune to ambivalence. We shall briefly go over the three outlines that Van Parijs presents, but keeping the doubts that we have presented, and then we shall move on with a different strategy: no longer finding a satisfactory Rawlsian version of the difference principle, but another, still Rawlsian grounding for a more solid egalitarian formulation of the difference principle. 
The first version of the DP in TJ establishes that "social and economic inequalities are to be arranged so that they are both (a) reasonably expected to be to everyone's advantage" ( $T J$, revised edition, p. 53). Following Rawls, Parijs identifies ambiguities in this formulation, requiring a more unequivocal version according to which the DP would be as follows:

Assuming the framework of institutions required by equal liberty and fair equality of opportunity, the higher expectations of those better situated are just if and only if they work as part of a scheme which improves the expectations of the least advantaged members of society. The intuitive idea is that the social order is not to establish and secure the more attractive prospects of those better off unless doing so is to the advantage of those less fortunate. (TJ, revised edition, p. 65)

So, Parijs concludes from this second formulation, apparently free from ambiguities highlighted by Rawls himself, exactly the same thing we generally suggested above regarding his DP. In other words, it allows for very non-egalitarian interpretations to be made of it: "all that is needed to justify an inequality, however large, is some improvement, however tiny, for the worse off, relative to the conceivably very depressed counterfactual situation of total equality between the expectations of the more fortunate and the less fortunate." (Parijs, 2003, p. 204)

Simply, Parijs finds in the third formulation of the DP, which Rawls presents as the simplest, an egalitarian commitment of a higher order, free of ambiguities. The formulation is:

Social and economic inequalities are to be arranged so that they are both (a) to the greatest benefit of the least advantaged and (b) attached to offices and positions open to all under conditions of equality of opportunity. (TJ, 83/

72 revised edition)

Parijs consider this a "far more demanding formulation" (Parijs, 2003, p. 204) and, within it, highlights the expression "to the greatest benefit". Only clause (a) relates to the DP and nothing more is said other than that inequalities have to be of the greatest benefit of the least advantaged. Is this enough? Rather than some benefit to the least advantaged, however small the crumbs, Rawls does in fact raise the stakes to the greatest benefit of those least advantaged people. But the greatest benefit relative to what came prior or the greatest benefit compared to all other beneficiaries of that inequality? If it is the former, the meaning of this formulation would end up being exactly the same as the previous one. If it is the latter, we would in fact be rejecting that there is any greater benefit for the most advantaged than the benefit achieved by the least advantaged. But can we be certain that this leads to less inequality? If the greatest benefit for the least advantaged is an aggregate benefit, it is not hard to imagine situations in which inequality would still grow extensively, particularly if inequality is already quite serious. Let us suppose, for example, that there are a million least advantaged people and only 10 most advantaged people. A million crumbs may satisfy the criterion of the greatest benefit for the least advantaged if the benefit for the most advantaged is "only" half a million crumbs. If these are distributed among only the 10 most advantaged, then inequality will increase drastically. Furthermore, if the interpretation is the strictest possible-according to which none of the most advantaged may obtain a greater benefit than any of the least advantaged-we can easily conclude that this is an excessive version that will certainly conflict with hierarchically superior principles of justice, starting with those pertaining to liberties. But neither of these is the interpretation we should make within the Rawlsian system of the "greatest benefit" for the least advantaged. As Rawls makes very clear in the outlines he makes before the third formulation of the DP, "the greatest benefit" does not refer to a comparison with either the previous situation or an absolute comparison with the benefit of the most advantaged, but to a comparison with the benefits that the least advantaged could have under the circumstances. This consideration, although indisputable, is not explicitly contained in any formulation of the DP, which means ambivalent interpretations may remain.

Although the democratic equality contained in the principles of justice has been the target of political criticisms as much from the right as from the left, we believe that Norman Daniels' reasoning remains extremely justified:

A society conforming to its three principles would probably assure people more equality than is provided in any society we see around us today-even the most egalitarian social welfare states. (Daniels, 2003, p. 243)

The challenge we are embracing is, then, within a Rawlsian grounding, and informed by his political thought in Justice as Fairness (JF), to propose another formulation of the DP immune to ambivalent interpretations that make growth in inequalities acceptable, even if against the more accurate interpretation of Rawls position in TJ.

\section{Deepening attention to the principle of fair equality of opportunity and the difference principle}

Next, will deepen attention to the relationship between the second principle of justice (and the two components thereof-the principle of fair equality of opportunity (FEO) and the difference principle) and the problem of promoting egalitarianism.

The second principle of justice regulates social and economic inequalities and makes them subordinate to the first, and they cannot restrict it. This means that basic liberties cannot become contingencies dependent on any considerations related to society's economic order. Furthermore, Rawls adds that the unconditional nature of basic liberties is found in a society that is not in a situation of either extreme abundance or extreme scarcity, therefore guaranteeing enough means for the normal functioning of the basic structure regulated by a political notion of justice.

The definitive formulation of the second principle is as follows:

Social and economic inequalities are to be arranged so that they are both:

(a) to the greatest benefit of the least advantaged, consistent with the just savings principle, and

(b) attached to offices and positions open to all under conditions of fair equality of opportunity. (TJ, revised edition, p. 266)

The two subprinciples-DP and FEO-establish regulatory conditions for social and economic inequalities and therefore implement distributive justice as a central feature of justice as fairness. In fact, the way Rawls justifies the existence of distributive policies goes back to the need to determine, in the basic structure of a well-ordered society, procedures that ensure the preservation of a fair social cooperation system from generation to generation. In other words, distributive justice can be justified by a procedural background justice that ensures conditions are preserved to sustain society itself in the very terms in which it has been regulated by a certain notion of justice. As explained in "The Basic Structure as Subject" (1977), a fair basic structure guarantees "background justice" (Rawls, 1977, p. 160) based on which the justice or fairness of agreements among individuals and associations can be assessed from a social standpoint. 
On the one hand, (b) is a principle of equality of opportunities that cannot be reduced equal treatment of all before the law-isonomy. It is more than that: an equality of opportunities that reaches down to the crucial material conditions needed to provide real, and not merely virtual, equality of opportunities. Rawls argues that those who have the same innate qualities and share the same level of motivation should have the same opportunities for success, regardless of their natural or social condition. This principle is different from the meritocratic principle, according to which the most talented people, or those that are more socially advantaged, have greater and better opportunities.

On the other hand, as already discussed, (a) is called DP and has a criterion for use in the maximin, although it is not necessarily a single criterion or even a necessary one. As a heuristic instrument, it is useful to consider the two principles of justice as the maximin solution to the issue of social justice. In the same way that, in accordance with the maximin rule, subjects choose the option in which the worst result is better than the worst results of the others, the choice of principles of justice such as fairness is made under the assumption that individuals are in the lowest social position, since their real social situation is unknown. This relationship comes from the fact that the two principles are those that any subject would choose for a notion of a society in which he or she was assigned his or her position by a "malevolent opponent" (TJ, revised edition, p. 132s). Despite this analogy, the two principles that govern basic institutions should not be confused with the rule underlying the choice to follow them. Rawls, then, avoids using the name maximin criterion of fairness for the DP and highlights a distinction between the two-while the maximin rule concerns rules for making choices in uncertain situations, the DP is a special criterion applicable, in the first place, to the basic structure of society through representative subjects whose expectations should be assessed using a list of primary social goods (Idem, p. 72s). Notwithstanding the practical validity of the maximin rule, its application as a moral principle for assigning social benefits is unacceptable (see Harsanyi, 1975), since it would lead society towards widespread impoverishment.

It is therefore important to shed light on the merely analogical relationship between the maximin rule and the $\mathrm{DP}$-both favour the worst situations-and untangle the reasoning that governs calculations for a principle for allocation purposes. Solving practical problems using the maximin rule leads to absurd results. For example, if medicines are scarce and the government decides to give them to terminally ill patients, it would end up making the situation worse for patients who would actually benefit from taking them. This decision collides with the inherent requirement of the DP which states that the situation of the least advantaged should be improved without making the social situation of all the others worse. In this specific case, it is not acceptable to refuse a cure to all those who have a chance at being cured.

Rawls acknowledges the irrational consequences of applying the maximin rule to real-world needs; especially because "(...) it seems extraordinary that the justice of increasing the expectations of the better placed by a billion dollars, say, should turn on whether the prospects of the least favoured increase or decrease by a penny" (TJ, revised edition, p. 136). This difficulty is also similar to applying the DP to the hypothesis illustrated by the following objection: since it aims to maximise long-term expectations of the least advantaged, the fairness of large increases or reductions in the expectations of the most advantaged may depend on small changes to the expectations of the others. This hypothesis is abstract and forgets that i) the notion of justice as fairness, inherent to both principles, applies to the basic structure of society as a whole; and ii) the occurrence of such contingencies is avoided at the outset by applying the principle of equal liberties and the FEO. Similarly, and more clearly, in "Some Reasons for the
Maximin Criterion" (1974), Rawls clarifies that the maximin rule does not influence the direct allocation of goods. Although suitable for the choice of principles for the basic structure of societymacro contexts-it is not suitable for micro contexts. It cannot be adapted, for example, "to how a doctor should treat his patients or a university its students" (Rawls, 1974a, p. 226). The principles of social justice are macro principles, therefore they cannot be tested or contradicted by "micro" applications (Rawls, 1974b, p. 235).

Against those who believe a very large aversion to risk to be the main reason for choosing the DP, Rawls demonstrates that adoption of the maximin strategy arises not from this but from a desire for stability in the social justice system introduced. This is also true because aversion to risk by parties in the original position is no less than the aversion felt by any normal person (Rawls, 1974a, p. 228) and aversion to risk alone is a no more decisive reason than the others underlying the choice of the DP over other alternatives: the fact that its application requires "much less information", its greater capacity as a "public principle," and "the strains of commitment" (Idem, p. 229).

The Rawlsian maximin strategy is not, therefore, so much a foundation of the DP as an argumentative strategy of justice as fairness against utilitarianism. But this is the first stage of the argument, in which principles of justice are chosen for how much they protect basic liberties and the FEO of risks arising from utilitarian social calculation, avoiding sacrifices of well-being for some people to maximise overall or average utility (Shenoy and Martin, $1982 / 3$, p. 132s). This is followed by a second stage, in which there is a search to find out if the distribution of income, wealth and social and economic opportunities should be governed by the DP or by a principle that maximises average utility (Rawls, 1974a, p. 238-242; p. 245-249). In other words, there is a survey on how economic and social advantages should be distributed in order to respect relations among free, equal citizens. Once the priority principles have been accepted, Rawlsian strategy emphasises the notion of "collective asset" in the tenet of mutual advantage implicit in the DP; according to this, no-one should make gains at the cost of depriving others.

With the aim of providing essential conditions for a more dignified life to the least advantaged, the second principle of justice aims to restore the principle of equal liberty-which eliminates the influence of social eventualities but approves a distribution of wealth and income according to the natural lottery (TJ, revised edition, p. 63s). Consider, for example, the FEO. It demands that job candidates are considered for their relevant talents and abilities while, at the same time, institutional measures are introduced to avoid incidental factors (class, race, gender, etc.) interfering in the normal development of potential. In turn, the DPl restricts inequalities to those that work to the greatest advantage of the group in the worst situation (Daniels, 2003: p. 241). With an egalitarian objective in sight, the latter principle establishes that inequalities due to birth and natural ability, because they are undeserved, require reparation-the "redress principle". So, "in order to treat all persons equally, to provide genuine equality of opportunity, society must give more attention to those with fewer native assets and those born into less favourable social positions" (TJ, revised edition, p. 86).

The DP is a principle of mutual benefit, in other words, it involves a situation of reciprocity. If we consider the existence of only two social groups-the most advantaged and the least advantaged-a society subordinated to the limits defined by the lexical priority of the equal liberties principle and the FEO can maximise the expectations of only one of the two groups. If the DP is accepted, the system will maximise the expectations of the less advantaged group. If it is not, it is preferable to maximise a weighted average of both groups. Nonetheless, this maximisation is doubly beneficial for the most fortunate: it compensates them 
for something that does not justify any prior right to benefits, natural and social features that are neither fair nor unfair; and for the importance it assigns to their expectations. The most advantaged therefore recognise that the well-being of each person depends on a scheme of social cooperation. And that the voluntary cooperation of all in a social system requires reasonable rules and particular care in improving the situation of the least advantaged. As a result, "they forego the idea of maximising a weighted mean and regard the difference principle as a fair basis for regulating the basic structure" (TJ, revised edition, p. 88).

A situation in which there are more than two social groups is more complex. Rawls treats this as a "chain connection": if the expectations of the least advantaged improve as a result of an increase in the expectations of the most advantaged, the same would happen for those in a medium position (TJ, revised edition, pp. 70-73). He shows how common it is when other principles of justice such as fairness are properly applied. In other words, in a perfectly fair organisation, contributions by those who are in the best situation spread throughout the social fabric. In such circumstances, the practical consequences of the DP approach those of the principles of efficiency and average utility, when measured by primary goods. Nevertheless, these principles do not lead to a continuation of expectations among subjects representing the $\mathrm{n}$ groups of a society, for which the DP presents a solution. It tells us that

in a basic structure with $\mathrm{n}$ relevant representatives, first maximise the welfare of the worst off representative man; second, for the equal welfare of the worst-off representative, maximise the welfare of the second worst-off representative man, and so on until the last case which is, for the equal welfare of all the preceding $\mathrm{n}-1$ representatives, maximise the welfare of the best-off representative man. (Idem, p. 72)

As well as these benefits, the DP also encourages an interpretation of the principle of fraternity (Rawls, 1968, p. 166s; TJ, revised edition, 90s). A fraternal society is a social union of social unions and does not foresee equality of conditions as a prerequisite (and this is, furthermore, not acceptable under the DP). By joining an association whose members share the same notion of justice, each individual guarantees the means crucial to pursuing their life plans-the principles of justice and fairness provide more favourable conditions to pursuing individual notions of good. Demonstration of stability reveals that individuals have a moral motivation in the first place, a sense of justice, that they are able to act accordingly and that this is not obstructed by any barrier from the theory of human nature. Egalitarian liberalism therefore seeks to show that, on the one hand, the sense of justice is realistic in psychological terms and dominates over the impulses of certain psychological tendencies (such as envy). On the other hand, it shows that fairness and goodness are compatible.

The question remains: are the inequalities permitted by the difference principle enough to incentivise social progress? If we believe, as Rawls did, that they are an incentive to the middle class' commitment to productive forms of work and to investment by capitalists in equipment and improving productivity, then we can believe that they are. This progress translates into gains in production, beneficial for the least advantaged group in the form of a supplement to income or wealth. The difference principle stipulates maximising the combination of this material gain with the social bases of self-respect, which in Rawlsian terms is the most important primary social good.

In a certain way, what happens with the growth of the difference principle in a rule of three that is the maximin criterion is the same as what happens with Adam Smith's argument in the analogy of the invisible hand. Although it is John Rawls himself, in Political Liberalism, who realises this and takes responsibility for the excessive emphasis on rational choice theory in TJ:
Here I correct a remark in Theory, p. 16, where it is said that the theory of justice is a part of the theory of rational decision. From what we have just said, this is simply incorrect. What should have been said is that the account of the parties, and of their reasoning, uses the theory of rational decision, though only in an intuitive way. The theory is itself part of a political conception of justice, one that tries to give an account of reasonable principles of justice. There is no thought of deriving those principles from the concept of rationality as the sole normative concept. I believe that the text of Theory as a whole supports this interpretation. (Rawls 1993, II n. 7, p. 53)

\section{For an advanced social democracy: property-owning democracy}

It is interesting to see that in the possible variations of the principles of justice-equal liberties, FEO and DP-most of the options at stake are notions of social justice that cover the contemporary ideological spectrum. We shall seek to explore how these differences can be identified through variation exercises. We will then enter into a discussion about the reasons that lead Rawls to argue for a notion of property-owning democracy (POD) and that place it on a much more egalitarian footing than welfare capitalism.

Heuristically, it is interesting to note the possibility of differentiating between the great ideological choices of the more contemporary party political framework by observing only its variations in behaviour when dealing with the three components of the Rawlsian principles of justice.

Libertarianism will commit to the principle of liberties and a merely formal principle of equal opportunities that essentially corresponds to isonomy, that is, equality before the law. Its defence is limited to the minimal state, in charge of security and organising the three sovereign powers: legislative, executive and judiciary. But without a social state to guarantee actual equality of opportunities, and even less so redistributive policies. Under libertarianism, support for the poorest springs from the will of philanthropists. This is largely the regime that Rawls calls laissezfaire capitalism.

Liberalism is committed to the principle of liberties and the FEO but not to the DP. Nonetheless, these commitments are enough for, further to the minimum functions of the state, there to be a social state that promotes the empowerment of citizens to access opportunities, one that guarantees, for example, a universal right to education. The fundamental reason why genuine liberalism involves accepting the demand for actual equality of opportunities relates to the central role played by the idea of universality of opportunities in it. It would clearly be illiberal for a society that professed to have freedom of opportunities-classic laissez-faire-while at the same time accepting opportunities to be removed by society.

Rawls's egalitarian liberalism is committed to the three components of the principles of justice and it is hard to find a closer ideological choice in the European political party tradition than classical social democracy. In fact, the state's intervention in this is restricted to guaranteeing the FEO as far as possible. It also implements redistributive policies that can be justified in several ways, including the fact that the FEO itself cannot be guaranteed without a policy, at a particular time, to allow and restrain inequalities. In the light of this, we shall analyse how close it is to property-owning democracy (POD) and liberal socialism (LS), as defined by Rawls, in contrast with welfare state capitalism (WSC).

Provided that it is democratic in the sense that it has representative democracy, with a separation of sovereign powers and the rule of law, it undertakes these principles of justice and adds to them another function of the state. As well as guaranteeing fair 
equality of opportunity and redistributive policies, it considers that the state should have the power to intervene in the economy, limiting the market economy in several ways. For example, by removing its sphere of influence in particularly sensitive fields, such as areas inherent to the welfare state, public health and education, or strategic production sectors on which the country is especially dependent.

Rawls appeals to rational judgement, but he does so within a framework that favours liberal economic rationality based on individual choices that maximise one's own interests. Particularly in the political liberalism stage, where the parties of the contract are representatives of democratic citizens, people who are free and equal with an extensive interest in exercising their capacities of rationality (to develop a notion of good) and fairness (sense of justice).

Rawls, despite concluding on the advantages of a certain egalitarianism with a liberal slant, does so under terms that are debatable in the eyes of anyone who does not identify with that framework. As if egalitarianism were accidental in a liberaldefensive line of thought (Mouffe, 1993). However, it is important to clarify something at this point. In the contemporary debate on social justice, the meaning of the term "equality" cannot be reduced to a description of people as equal beings or egalitarian conditions; it is used, on the other hand, to justify a more equal distribution of goods, services and opportunities among people. It is in accordance with this second meaning that the Rawlsian principles of distributive justice take on egalitarian characteristics (see Gutmann, 1980, p. 2). By connecting the idea of justice to an egalitarian allocation of social goods, Rawls introduces an important restriction: individuals are treated as equals by eliminating not all inequalities, but only those that favour certain people. An inequality that is beneficial for any individual, in that it deals with socially useful skills and energies, will be accepted by all. The idea that inequalities that broaden our initial fair share are acceptable and inequalities that hinder it are not is the core of the theory of justice as fairness. Rawlsian egalitarianism therefore demonstrates the social relativity of natural differences between individuals (see Cabrita, 2007, p. 252).

Can applying the Rawlsian principles of justice overcome the failings of the social democratic welfare state-the accumulation of wealth and worsening inequalities? At first glance, we could say that Rawls's egalitarian liberalism, with its defence of justice as fairness (with an emphasis on reciprocity) opens a path to building a more egalitarian society. Although institutionally harmful to welfare state capitalism (WSC), which encourages social polarisation between the rich and poor and assigns a determining role to "intermediaries" in the redistribution of social assets (dualist model of the welfare state), Rawlsian liberalism, especially through the debate it triggered regarding the DP, seems to shed light on the possibility of regenerating the full model of the welfare state. This model, which has been most extensively perfected in the social democratic systems of the Scandinavian countries and corroded by the imperatives of globalisation since the last decades of the 20th century, took on a much more demanding social programme than the dualist model.

Presumably, and given the familial association between social democracy and social liberalism in European political language, the attempt to restructure this welfare state model in light of the POD may seem paradoxical. In this sense, it is worth reminding that this regime was idealised by economist James Meade in the 1960 s, with the aim of reconciling the diffusion and equalisation of ownership of private property with the growth of state property in the British economy as a whole. In these terms, the POD represents not so much an alternative to LS (as it does to WSC) as a supplement to it. Rawls closely follows Meade's understanding of the POD (see Rawls, 2001, p. 135, note 1), and subsequently invites a reading that the delay in the analysis of this regime cloaks a leaning towards a LS (see Edmundson, 2017, p. 76s), “a regime was envisaged by the English Labour Party and the German Social Democrats (Rawls, 2008, p. 150, note 12).

On the other hand, in the strictly economic sense and in light of the republican liberal theory of justice (Thomas, 2017), Meade's model of the POD may also be interpreted as a form for individuals to safeguard their liberties in face of the dangers of oligarchical drift and domination.

Without lingering on the recent debate on which of the two ideal regimes - the POD or SL-is the most apt for implementing the principles of justice as fairness (Edmundson, 2017; Thomas, 2017), we will focus our analysis on Rawls, who, while not stating preference for one regime over another, puts emphasis on the POD.

In TJ, Rawls identifies the most suitable ideal regimes for applying the principles of justice as fairness-POD and LS regimes-and he made a vague distinction between POD and WSC-a small gesture that stimulated the erroneous reading of his theory as a "defence" of WSC. As a result of this misunderstanding, at the end of the 1980s, the philosopher went into more detail about the characteristics of POD that set it apart from WSC (see Rawls, 2001, p. 135-179). The conclusion of his reflections on this theme in $J F$ support the proposal made in $T J$ on the most suitable democratic regimes for applying his principles of justice. Rawls writes:

Both a property-owning democracy and a liberal socialist regime set up a constitutional framework for democratic politics, guarantee the basic liberties with the fair value of the political liberties and fair equality of opportunity, and regulate economic and social inequalities by a principle of mutuality, if not by the difference principle. (2001, p. 138)

Due to the dispersion of ownership of capital and resources, both regimes stop economic and political powers from being concentrated into the hands of a minority. The political side of LS is characteristically pluralist, and its economic side is co-inhabited by a range of independent companies operating in a free market. But, because the means of production and natural resources in this regime are public property, its distributive function is highly limited; on the other hand, the private property system uses prices in different ways to achieve both objectives. The choice of one of these two regimes is due to a society's historical circumstances, its tradition of political thought and practice.

However, Rawls did not focus so much on the differences between POD and LS (the issue of property in the means of production) as on the differences between POD and CWS. Unlike LS, both the latter regimes allow the means of production to be privately owned, which is more favourable for implementing the DP (see Freeman, 2007, p. 226). Rawls's focus on POD and the influence of Krouse and McPherson's (1988) interpretation can be seen. According to this analysis, what as at the heart of the disparities between the two regimes is the difference in strategy in the provision of justice in the political economy: while WSC accepts a substantial inequality in the initial distribution of property and natural talents as a given and, therefore, seeks to redistribute income ex post, POD searches for greater equality in the distribution of property and natural talent ex ante, with less emphasis on subsequent redistribution measures.

It is indeed against the backlight of WSC, especially the focus on its shortcomings, that Rawls describes POD. Following the list presented by Freeman (2007, p. 226-231), we highlight the most relevant for our goal:

1. While WSC allows monopolies of the means of production by a small class, POD promotes wider ownership of the means of production so that workers can control the real 
capital and their working conditions as private owners, members of trade unions or worker cooperatives (see Rawls, 2001, p. 139). Lying between trade unionism and WSC, POD includes several business management models-from the traditional one, controlled by owners, to the model common in some social democratic European countries (such as Germany), co-led by management and workers, and models controlled by workers, such as self-managed cooperatives (Freeman, 2007, p. 220);

2. In POD there are no colossal disparities in income and wealth between the most and least advantaged, as there are in WSC. So, adding to the effects of the DP, protection of the fair value of political liberty and the FEO require a reduction in gross inequalities. In POD, great disparity in wealth is discouraged by taxes on assets, inheritance and gifts. A "progressive inheritance tax" aims to avoid extensive concentrations of wealth passing from generation to generation (see Rawls, 2001, p. 161);

3. By assuming the fair value of political liberty, POD, unlike WSC, supplies public funding for electoral campaigns, restricting private funding, and provides public forums for debate among alternative political agendas;

4. POD provides a greater FEO than WSC. For example, workers not only have the chance to control the capital used in the performance of their duties but have greater control and protection in their workplaces. In other words, POD inhibits relations of domination and degradation in the division of labour. While it does not remove the division of labour in a general sense, POD eliminates its worst aspects: "no one be servilely dependent on others and made to choose between monotonous and routine occupations which are deadening to human thought and sensibility" ( $T J$, revised edition, p. 464);

5. The social minimum is higher in POD than in WSC, since it is established at the point where, taking salaries into account, it maximises the expectations of the least advantaged group (Idem, p. 252). In other words, its aim is not to maximise the total amount of domestic wealth (as in WSC) or the average level of income and wealth. And this is guaranteed by family and special allowances in the event of illness or unemployment and by mechanisms such as gradual supplements to income-negative income tax (Idem, p. 243);

6. Rather than income tax, which discourages from work (people's contributions to the production of goods and services), POD applies a proportional expenditure tax. This is a tax that applies only when a certain level of consumption is reached, as Rawls highlights, "by taxing only total expenditures above a certain income, the tax can be adjusted to allow for an appropriate social minimum" (ibidem);

7. In POD, all physically able people are encouraged to work. The state's stabilisation sector has the task of reasonably maintaining full employment-when the economic system fails to provide full employment, the state takes on the role of "employer of last resort" (civil service, national services, etc.). WSC provides a social minimum to all citizens, even when they can work but prefer not to, and makes citizens dependent on its social system. In contrast, POD citizens, who are committed to fair and equal cooperation, should contribute with their part and not take advantage of the efforts of others - this is an application of the principle of fairness (see TJ, revised edition, p. 95) and reflects its underlying moral commitment. In POD, the social minimum "is rather a payment that democratic citizens are $d u e$, as a matter of right, for their taking part in an complying with just terms of social cooperation" (Freeman, 2007, p. 230);
8. While under WSC, the least advantaged employment is remunerated with a minimum fixed salary paid by the employer and aims to discourage the creation of new jobs, under POD, those who have a low income in the labour market are supported by public income supplements. This measure is in accordance with the difference principle, since its aim is to bring the least advantaged up to the reasonable social minimum it requires;

9. Finally, in order to meet the requirements necessary for FEO among free and equal citizens, POD provides universal health care and universal education by applying public funds. The expectations that ensure provision of health care at a certain level are included as part of the social minimum. The state is responsible for providing equal opportunities of education and culture to people with similar abilities and motivations, through funding for private schools and by setting up a public education system.

Rather than the simple redistribution of income in favour of those who, due to misfortune or accident, find themselves with a less than decent standard of living, POD's social justice goes beyond CWS's, leaving citizens with suitable means to properly deal with their matters and take part in social cooperation. In these cases, the state not only democratises wealth but empowers the group targeted by social policies-the vision of a citizenowner in the POD's social programme works against the negative effects on self-respect and mutual respect in the individualcustomer vision of CWS's social assistance.

\section{For an advanced social democracy: degrowthist formulation of the principle of justice and framework rules}

In our understanding and, we are persuaded, in John Rawls's, as we have sought to demonstrate, it is not the application of a maximin criterion that should be at stake in this discussion, but rather the intentions of the DP and what it should serve. Inequality does not have to pay a tax to equality, it has to be a contribution to equality of opportunities. If it is not, we eventually accept paying tax as being egalitarian, but we are wrong, because that payment in truth buys an unlimited right to inequality. A DP should stipulate that a new inequality can be accepted not because it leaves the least advantaged better off than they were, but simply because that new inequality leads to greater equality of opportunities for the social system.

It is important to make some clarifications about using this notion of inequality. Inequality is not good or bad in itself, and the same is true for equality. A glaring inequality or an equality without liberty are both ways of reducing the horizon of opportunities for many in favour of others. For that reason, we should aim for, as a valuable part of the rules, the widest horizon of opportunities possible, fairly distributed among all. In a Rawlsian context, we can call this FEO.

Faced with this framework, we propose formulating a more robust version of the DP that hinders new inequalities via an explicit regulation clause prohibiting an aggregate rise in inequality. Thus, something in the style of the clause proposed by Cohen (1988/1989), according to which a factor should be taken into consideration that reflects the degree to which income is concentrated, using the Gini coefficient. Furthermore, talking about a liberal-egalitarian notion of justice would be at best unclear and at worst a falsehood.

Unlike a strict principle of equality, an egalitarian principle concludes that normative equality of liberties and opportunities, which is contained in the first and second principles of justice, requires substantial material equality. The DP, although lexically subordinate to the remaining principles, is a condition that, if not met, leaves the others oppressed and under siege. What general 
formulation can we propose, then, for a DP free from ambivalences, indisputably beyond the commitments of welfare capitalism and social liberalism, to match the commitments of POD or LS? A formulation that, in short, is explicitly compatible with a non-assistencialist perspective, that does not focus on the most vulnerable but also pursues a universal perspective, as in fact happens with the other principles of justice proposed by Rawls.

On the positive side, a fairer formulation of the DP should be degrowthist, actually demanding that the accumulation of inequalities degrow. The formulation could be as follows:

New, discrete inequalities are only permissible if, as well as meeting the maximin criterion, they degrow social inequalities overall.

But how could such an abstract DP be implemented? The egalitarian DP merely provides a criterion to fairly regulate the practice of inequality. This was the case with Rawls's DP and it is the case for this reformulation. The difference lies in the fact that this formulation intends to preserve and encourage equality. But it does not differ from the first in the need for implementations, which we could call rules.

For these rules, we propose the following:

1. Rule on the prevention of intergenerational inequality: reduction in accumulation through inheritance taxes, tax on large fortunes.

2. Rule on egalitarian impact assessment studies.

3. Rule on regulating the range of salaries.

Reduction in intergenerational inequality. The accumulation of inequalities is not only the result of a notion of social justice that, interpreted ambivalently, may not be as egalitarian as it appeared. It is also the result of conditions, which apparently come before political considerations, that organise the social experience into a continuum over time in which nothing is lost. This is the only way accumulation can be enabled that, without explicit action, will not stop growing. Building that artificial "spontaneity" induces, as if it were natural, the production and preservation of inequalities and leads to the belief that reducing it is not, on the other hand, natural. This is a political construction and is, of course, politically debatable.

It is therefore necessary to rebuild a legal translation of our relations with time to introduce more ways of reducing accumulation, one that values it as a reduction in inequality: the two faces of Janus, one of which, symbolically, in the original myth, looked to the past and the other to the future. It involves replacing one artificial construction with another, but the second is more ecological, through legislation, public policies, collective human will and action. And there are several lines of action that can reintroduce entropy and balance in the socio-economic process of time.

The idea of intergenerational justice takes root in the demand for previous generations to leave following generations with the same conditions they enjoyed, not depleting resources or causing a lack of environmental sustainability. But in a society that accumulates and concentrates wealth and increases inequalities, reproducing them and amplifying them from generation to generation, it is imperative to broaden the concept of intergenerational justice to include regulation of inequalities. Broader intergenerational justice should commit preceding generations to not transmitting more inequalities to future generations than the ones they encountered. Not leaving our children more inequalities than we received involves a new notion of legacy, but one that is shared socially. Established in that way, intergenerational equality of opportunities must limit the right to transmit acquired and accumulated privileges, even if they were acquired and accumulated fairly, deservedly and as the result of hard work. In order to do this, inheritance taxes must be established, along with other policies that ensure the generations that come after us are not condemned to face greater inequalities than we were. The price to pay for a society of inheritors is a society of debtors and the memory of debts. The Biblical pardon every seven years already understood the need to dilute the memory of egoism into social act of forgetting.

Rather differently, Rawls justifies the need for the practice of intergenerational justice as a condition needed to guarantee the bases of society itself. If society is seen as a fair association of cooperation that spans generations, then each generation must ensure that it leaves behind the fair basic structure of society for those that come after it. That guarantee is made by respecting the just savings principle, which works diachronically across generations as the DP does synchronically for each generation. Naturally, the two coincide in each present time, making it a clause included in the formulation of the DP.

Egalitarian impact assessment. A second framework rule that structures the permissibility of inequality should restrict government activity, introducing, based on the contract that brings citizens together in a political community, an obligation to accompany the country's economic governance with an egalitarian impact assessment.

This obligation should be grounded in the constitution and its concrete result would be prior scrutiny of draft state budgets, as well as any possible amending budgets, by a competent (and independent) authority, with all measures that affect the state's income and expenditure being submitted to an egalitarian impact assessment. This scrutiny may be included in the functions of the Court of Auditors. In Portugal, for example, "the Court of Auditors is the senior organ for the scrutiny of the legality of public expenditure and for judging the accounts which the law requires to be submitted to it" (Art. 214 of the Portuguese Constitution). For this, proposed budgets should be submitted to the Parliament together with a study regarding their impact on equality, overseen beforehand by the Court of Auditors, and with an explicit reference to the forecast evolution in social inequality indicators.

Range of salaries. The third structuring rule should establish a maximum range of salaries by setting salary limits when public money is involved, limiting the right to a maximum income through a reasonable comparison, in terms of dignity and social justice, with the minimum income. This should apply to public services and private services that involve some type of public support, whether in the form of direct funding or exemptions and other tax benefits. And if there is no public involvement in remuneration, there should still be a demand for robust progressive taxation that is truly able to counteract the marked trend towards increases in wage ratios; for example, the more than $1000 \%$ increase in the CEO-to-worker pay ratio since the 1950 s reported by Bloomberg in 2013. A degrowth perspective, or at least a non-growth perspective, of inequalities should also involve the degrowth or non-growth of wage ratios, of which the CEO-toworker pay ratio is a clear indicator.

The commitment to a degrowthist difference principle formulated generally but that can be implemented in rules is possible at the different scales involved in a society's life, whether in terms of intergenerational justice or in democratically chosen public finances and a fair distribution of wages. With this general formulation and a set of concrete implementation rules, we can find social democracy's commitment to egalitarianism, 
extensively justified by a Rawlsian base, is better grounded and free from ambivalences. And it allows us to bring the principle of difference into the emerging degrowth paradigm, which urgently seeks to configure inequality as one dimension among several whose growth is problematic in a context of global interdependence and scarcity of resources.

Received: 1 March 2019 Accepted: 22 May 2019

Published online: 11 June 2019

\section{References}

Cabrita MJ (2007) O Liberalismo, a Justiça Social e o Papel do Estado: As Propostas de John Rawls e Robert Nozick. UNL, Lisbon

Cohen J (1989) Democratic equality. Ethics 99(4):727-751

Daniels N (2003) Democratic equality. Rawls's Complex Egalitarianism. In:Freeman S (ed) The Cambridge Companion to Rawls. Cambridge University Press, Cambridge, p. 241-273

Edmundson WA (2017) John Rawls reticent socialist. Cambridge University Press, Cambridge

Freeman S (2007) Rawls. Routledge, London and New York

Gutmann A (1980) Liberal equality. Cambridge University Press, Cambridge

Harsanyi JS (1975) Can the maximin principle serve as a basis for morality? A Critique of John Rawls's Theory. Am Political Sci Rev 69(2):594-606

Krouse R, McPherson M (1988) Capitalism, "Property-Owning Democracy" and the welfare state. In: Guttmann A (ed.) Democracy and the welfare state. Princeton University Press, Princeton, p. 79-105

Mouffe C (1993) The return of the political. Verso, London/New York

OECD (2015) In It Together: Why Less Inequality Benefits All, OECD Publishing, Paris, https://doi.org/10.1787/9789264235120-en

Parijs PV (2003) Difference principles. The Cambridge companion to John Rawls. Cambridge University Press, Cambridge UK, p. 200-240

Piketty T (2013) Le Capital Au XXIe Siecle. Editions Du Seuil, Paris

Rawls J (1968) Distributive justice: some addenda. In: Freeman S (ed) Collected papers. Harvard University Press, Cambridge, p. 154-175. 1999

Rawls J (1971) A theory of justice (revised edition). Harvard University Press, Harvard

Rawls J (1974) Some reasons for the Maximin criterion. In: Freeman S (ed) Collected papers. Harvard University Press, Cambridge, 1999, p. 225-231
Rawls J (1974) Reply to Alexander and Musgrave. In: Freeman S (ed) Collected papers. Harvard University Press, Cambridge, 1999, p. 232-253

Rawls J (1977) The basic structure as subject. Am Philos Q 14(2):159-165

Rawls J (1993) Political liberalism (revised edition). Columbia University Press, New York

Rawls J (2001) Justice as fairness: a restatement. Harvard University Press, Cambridge

Rawls J (2008) Lectures on the history of political philosophy. Harvard University Press, Cambridge, Ed by Samuel Freeman

Scheidel W (2017) The great leveler violence and the history of inequality from the stone age to the twenty-first century. Princeton University Press, Princeton

Shenoy PP, Martin R (1982)/3) Two interpretation of the difference principle in Rawls's theory of justice. Theoria 48/9:113-141

Thomas A (2017) Republic of equals: predistribution and property-owning democracy. Oxford University Press, New York

\section{Additional information}

Competing interest: The authors declare no competing interests.

Reprints and permission information is available online at http://www.nature.com/ reprints

Publisher's note: Springer Nature remains neutral with regard to jurisdictional claims in published maps and institutional affiliations.

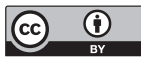

Open Access This article is licensed under a Creative Commons Attribution 4.0 International License, which permits use, sharing, adaptation, distribution and reproduction in any medium or format, as long as you give appropriate credit to the original author(s) and the source, provide a link to the Creative Commons license, and indicate if changes were made. The images or other third party material in this article are included in the article's Creative Commons license, unless indicated otherwise in a credit line to the material. If material is not included in the article's Creative Commons license and your intended use is not permitted by statutory regulation or exceeds the permitted use, you will need to obtain permission directly from the copyright holder. To view a copy of this license, visit http://creativecommons.org/ licenses/by/4.0/.

(C) The Author(s) 2019 